\title{
Cooking as a source of indoor air pollution in rural areas of Tanzania
}

\author{
Msafiri M. JACKSON \\ Department of Environmental Engineering, University College of Lands and Architectural Studies, ardhi \\ university, P.O. Box 35176, Dar es Salaam, Tanzania. \\ E-mail address: msafiri@uclas.ac.tzor msafirijackson@hotmail.com; Telephone 255-744263995, \\ Fax 255-22-2775391
}

\begin{abstract}
This study was concerned with the assessment of the contribution of cooking fuelwood, charcoal and kerosene to indoor air pollution in households in Msangani, Chahua and Kazimzumbwi villages in the Coast Region, Tanzania. It has also assessed the performance of Single Compartment Model in predicting indoor pollution levels under Tanzania conditions. The methods used in this study were household survey, measurements, and observation. The pollutants measured were Carbon monoxide (CO), Sulphur dioxide $\left(\mathrm{SO}_{2}\right)$ and Nitrogen oxides (NOX) using a combustion analyzer CA-6200-CALc manufacured by RAECO of USA, and Suspended Particulate Matter (SPM) using a filter and vacuum pump. It was observed that $97.3 \%$ of the 112 families surveyed utilized simple "three stones" fires for cooking. Other observed cooking facilities in the study areas were charcoal stoves and kerosene stoves. The overall pattern shows that the population in the three villages spent about $76.8 \%$ of their time indoors. The hourly indoor average SPM levels during cooking period ranged from $13571 \mu \mathrm{g} / \mathrm{m} 3$ to $305798 \mu \mathrm{g} / \mathrm{m} 3$. Compared with SPM levels recorded in similar studies, these values were much higher, and may contribute to health problems observed in the study areas. The CO concentrations before cooking, for households that use fuel wood, exceeded the WHO hourly standard of 30 $\mathrm{mg} / \mathrm{m} 3$ in $69.4 \%$ of the surveyed households, while the concentrations for those households using charcoal and kerosene were zero. The overall average $\mathrm{CO}$ concentrations in $\mathrm{mg} / \mathrm{m} 3$ at all households during cooking were $325 \pm 211$ and $148 \pm 44$ when fuelwood and charcoal biomass were used respectively. The measured values of CO were above the recommended WHO guidelines with an hourly objective value of $30 \mathrm{mg} / \mathrm{m} 3$. A Single Compartment Model provided a satisfactory approximation of the measured $\mathrm{CO}$ concentrations with an average ratio of measured/modelled $\mathrm{CO}$ concentration at $1.1 \pm 0.3$. The study recommends improvement to the ventilation system including the provision of an adequate number of windows and installation of chimneys for removal of combustion pollutants from indoor environment.

(C) 2009 International Formulae Group. All rights reserved.
\end{abstract}

Key words: Biomass; cooking; fuelwood; indoor air pollution.

\section{INTRODUCTION}

Historically, public health attention has focused mainly on the risks from outdoor air pollution. Certainly, the early estimate of the global burden of diseases from air pollution only addressed the impact from outdoor sources (Hong, 1995; Murray and Lopez, 1996). Even today, most researchers continue to emphasize outdoor air pollution, which is not surprising given that vehicular and industrial emissions in urban areas for both the developed and developing world are rising at an alarming rate. The recent evidence indicates that outdoor air pollutants could have a marked effect even at low ambient levels (WHO, 1999). In Tanzania, researchers have shown limited interest in outdoor air pollution, particularly in studying how motor vehicles pollute the air. The few studies carried out in Dar es Salaam include those conducted by NEMC (1993), Othman (1996), Musabila (2002) and Jackson (2004, 2005). 
These studies assessed the pollution from motor vehicles in the urban area of Dar es Salaam. They reported significant levels of pollution from sulphur dioxide $\left(\mathrm{SO}_{2}\right)$, Suspended Particulate Matter (SPM), Carbon monoxide $(\mathrm{CO})$, Nitrogen dioxide $\left(\mathrm{NO}_{2}\right)$ and Particulate lead $(\mathrm{Pb})$. A number of studies have been reported in the area of indoor air pollution in Asia, Africa and South America, where most of the developing countries are found. It is in those countries where low grade fuels are still predominantly used. The first impact of indoor air pollution on the health of the people in developing countries was reported as early as 1968 (Cleary and Blackburn, 1968; Sofoluwe, 1968). More recent studies on indoor air pollution from solid fuels have been conducted in various developing countries such as China (Fischer and Koshland 2007; Mestl et al., 2007), Zimbabwe (Rumchev et al., 2007), Bangladesh (Dasgupta et al., 2006), and India (Balakrishnan et al., 2004). Kitchen smoke has been identified as major killer and several recommendations given on how to improve indoor air quality in developing countries (Warwick and Diog, 2004). The primary source of indoor air pollution in developing countries has been identified as emission from low grade fuels, especially the forms of biomass used for cooking and heating in open fires or rudimentary cooking stoves with inadequate provision of smoke removal from the indoor environment. In rural areas of Tanzania, $95 \%$ of the population use biomass such as fuel wood, agricultural residues, cow dung and charcoal for cooking, heating and lighting purposes (United Republic of Tanzania Energy Policy, 2000). The remaining $5 \%$ of the population use other types of fuels such as kerosene, diesel, dry cells, grid and non- grid electricity, biogas, solar, wind and other renewable sources of energy (United Republic of Tanzania Energy Policy, 2000). The policy further estimates that only about $1 \%$ of the rural population has access to electricity from the national grid. The common methods used for burning fuel wood and charcoal are the three -stone stove type and the simple metal stove respectively. The use of the three-stone stove with fuel woods has been reported to produce large amounts of air pollutants in the indoor environment. The pollutants are estimated to have been responsible for 2.7 percent of the global burden of diseases (WHO, 2002).

Exposure to the pollutants from fuel wood has also been shown in several recent studies to be causally linked to several health effects, especially for women, who usually do the cooking activities using these fuels and young children, who spend most of their time close to their mothers (Parikh, et al., 2004). A study by Mtango et al. (1991), in Bagamoyo district of Tanzania regarding the risk factors for deaths among the children under five years old, revealed the significant levels of deaths for children who sleep in rooms where cooking with fuel wood was done. Although the study reveals that the mortality rate for less than 5 years children is significant, and that it is associated with indoor air pollution (Mtango et al., 1991), the study did not go further to identify the type and quantify levels of these pollutants in the indoor environment. Assessment of indoor air pollution from the combustion of wood fuels and kerosene in Tanzania has rarely been reported. The levels of pollutants are not well established. This study aims to measure the levels of selected air pollutants in the indoor environment at Msangani village Coast Region and test the performance of a Single Compartment Model in predicting gaseous pollutants concentrations in a kitchen. This mathematical model has been tested by using data collected in China (Zhang 1999).

\section{MATERIALS AND METHODS Fieldwork Sites}

This study was conducted in three rural villages in the Coast region. The Coast Region is situated in the Eastern part of Tanzania mainland, along the Indian Ocean Coastal Belt (Figure 1). The chosen villages were from three different districts in the Region: Msangani (Kibaha District), Chahua (Bagamoyo District), and Kazimzumbwi (KisaraweDistrict).

\section{Household survey}

A household survey was conducted via a questionnaire in a total of 112 households in the selected villages. The questions captured information on socio-economic characteristics, demographic, type of fuel used for cooking and consumption rates, cooking characteristics, housing and kitchen 
characteristics, and population time-activity budget. The study surveyed 45 households in village. The surveyed households were selected randomly.

The collected information was analysed by using SPSS software. Energy source data for Chahua and Kazimzumbwi village were analyzed by applying multiple response concepts since most of the families in these villages use more than one fuel source.

\section{Suspended Particulate Matter (SPM)}

A vacuum pump fitted with a filter paper was used to determine SPM concentrations. The weight of filter paper was measured prior to collection of SPM. The sampling train was placed inside the kitchen. The filter was mounted in its holder and fixed at a height of $1 \mathrm{~m}$ with a horizontal distance of $1 \mathrm{~m}$ from the fireplace. The horizontal and vertical locations correspond to the breathing zone of a person sitting in the kitchen. Air was
Msangani village, 22 households in Chahua village and 47 households in Kazimzumbwi sampled for a period of 1 hour at a flow rate of $3 \mathrm{~m}^{3} / \mathrm{hr}$. After sampling the filter was reweighed and the SPM concentration determined (Jackson, 2005).

Sulphur dioxide, Nitrogen oxides and Carbon monoxide

The concentrations of these pollutants in the indoor environment were established before, during and after cookings. An electrochemical combustion analyzer, CA6200-CALc manufactured by RAECO of USA was used to measure carbon monoxide (CO), sulphur dioxide $\left(\mathrm{SO}_{2}\right)$ and nitrogen oxides (NOx). The analyzer was calibrated prior to sampling.. The electrochemical combustion analyzer CA-6200-CALc have been described in a previous work (Combustion Analyzer CA-6200-CALc. Manual).

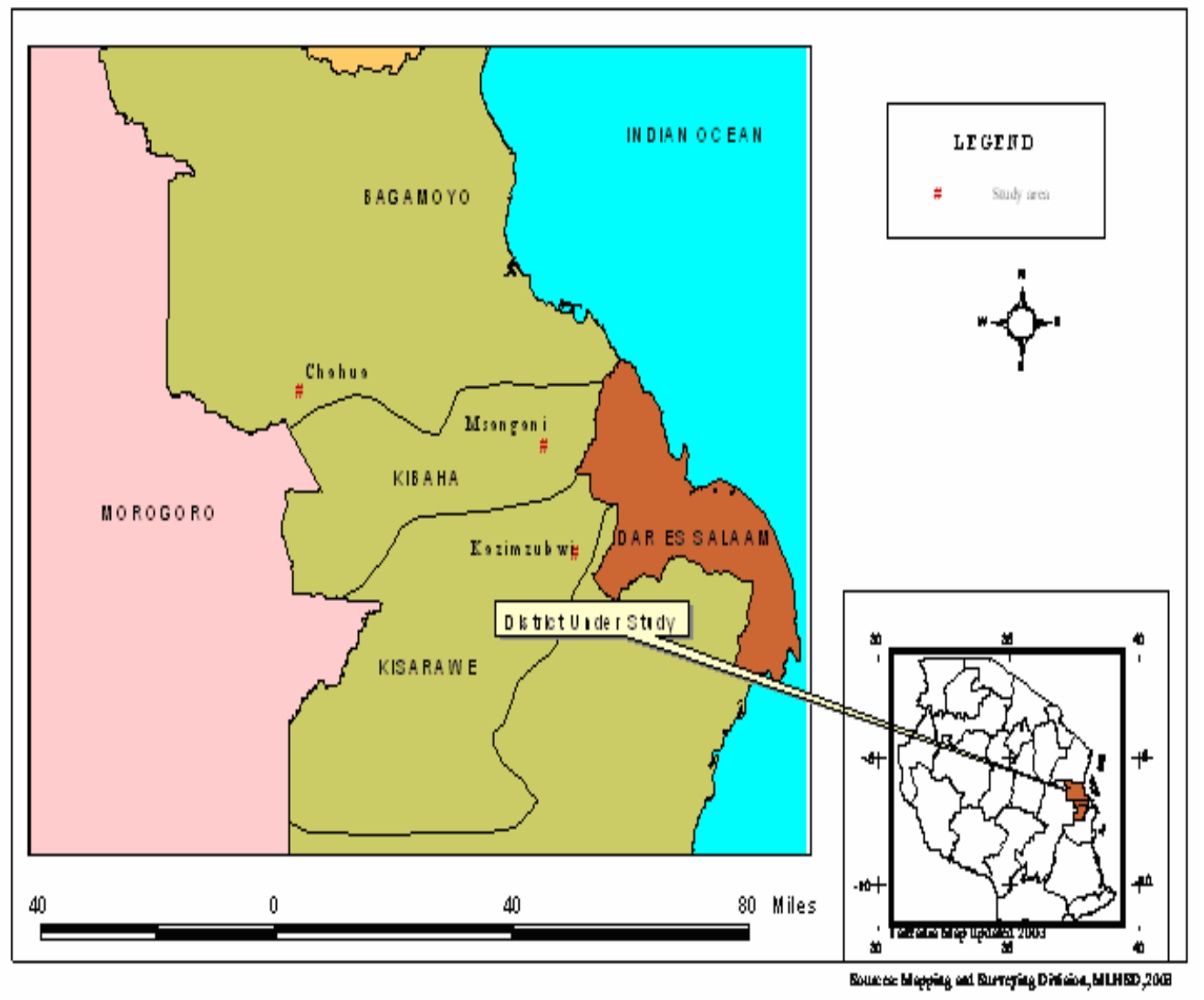

Fig. 1: Location of the study area 


\section{Model Application}

The Single Compartment Model is used to predict gaseous pollutants concentrations in Msangani village households. In this study, the model was used to predict the concentrations of carbon monoxide released from the burning of fuel wood in the kitchen. Carbon monoxide is the only pollutant considered due to the lack of some model parameters such as emission factors for other pollutants. Assuming a steady state flow rate and conducting a mass balance in the kitchen, the following mathematical model is obtained:

$$
\frac{d c(t)}{d t}=\frac{F E_{f}}{V}-S C(t)
$$

where,

$\mathrm{F}=$ Fuel burn rate $(\mathrm{kg} / \mathrm{h})$

$\mathrm{E}_{\mathrm{f}}=$ fuel mass based emission factor $(\mathrm{g} / \mathrm{kg})$

$\mathrm{T}=$ time for complete combustion of the fuel (h)

$\mathrm{V}=$ Volume of the kitchen $\left(\mathrm{m}^{3}\right)$

$\mathrm{S}=$ Air exchange rate or ventilation rate $\left(\mathrm{h}^{-1}\right)$

$\mathrm{C}(\mathrm{t})=$ Concentration at time $\mathrm{t}$

Using Equation 1 and appropriate initial and final conditions, the average concentration $\mathrm{C}$ for the entire burning duration ( $\mathrm{t}$ ranging from 0 to $\mathrm{T}$ ) was established to be:

$$
\bar{C}=\frac{F E_{f}}{V S}\left[1+\frac{1}{S T}\left(e^{-S T}-1\right)\right]
$$

where,

$\mathrm{T}=$ time for complete combustion of a fuel (time for cooking of a meal) (h).

Fuel burn rate $(\mathrm{F})$ was determined by conducting a survey to establish the fuel wood consumption per household and corresponding burning duration. The fuel wood consumption was determined by weighing the amount of wood used for cooking. Fuel wood was measured before cooking in the morning and the unused fuel wood was again measured after cooking in the evening in order to quantify the daily burnt fuel for a household. Several households were involved in the study. The average fuel wood consumption per household per day for Msangani village was determined to be $5.8 \mathrm{~kg}$ based on 42 households using this type of fuel. Assuming even fuel consumption per meal preparation and since meal preparation was done three times in most of the surveyed households; the fuel wood consumption per household per day was divided by three in order to determine the average fuel wood consumption per household per meal. Through the household survey, the average time for preparing a meal (T) was established to be 1.91 hrs. The burn rate $(F)$ was determined by dividing the fuel wood consumption per household per meal with the duration for preparing one meal giving an average burn rate of $1.02 \mathrm{~kg} / \mathrm{hr}$ for this study.

Ventilation rates for most kitchens in the rural areas of developing countries range from $10 \mathrm{~h}^{-1}$ to $19 \mathrm{~h}^{-1}$ (Zhang et al., 1999). The ventilation rate adopted for this study is the linear average of the given range which is $14.5 \mathrm{~h}^{-1}$.

Fuel - mass based emission factor ( $\mathrm{g}$ pollutant/kg-fuel) is a factor which shows the mass of pollutant generated through combustion of a unit mass of cooking fuel. The emission factor used in this study is 42.5 $\mathrm{g}-\mathrm{CO}$ per kg wood fuel (Zhang et al., 1999).

The volume of the kitchen (V) was obtained from the household survey.

\section{RESULTS \\ Household survey \\ Household energy}

The fuel use pattern assessment has revealed that, the majority of households use wood for cooking, followed by charcoal (Table 1). Agricultural residues and kerosene were mostly used at Kazimzumbwi and Msangani villages respectively. Kerosene stoves were used in Msangani village only.

The total fuel utilization percentage for Kazimuzumbwi and Chahua are higher than $100 \%$ since most of the families in these villages used more than one fuel type.

\section{Cooking characteristics}

In all the three villages, people cook three times per day. The time consumed for cooking the different types of food ranges from 45 minutes to 3 hours per meal. The person who mostly does the cooking in the interviewed households is the mother/women who normally sit at a distance which is less than $0.5 \mathrm{~m}$ from the stove while cooking. Occasionally, children and other family members will surround the fire in order to warm themselves up. The percentage of 
Table 1: Fuel type used in study areas.

\begin{tabular}{lllll}
\hline \multicolumn{1}{c}{ Fuel type } & \multicolumn{1}{c}{$\begin{array}{c}\text { Msangani } \\
(\mathbf{N = 4 5 )} \\
\mathbf{\%}\end{array}$} & $\begin{array}{c}\text { Kazimzumbwi } \\
(\mathrm{N}=41) \\
\mathbf{\%}\end{array}$ & $\begin{array}{c}\text { Chahua } \\
(\mathrm{N}=26) \\
\mathbf{\%}\end{array}$ & $\begin{array}{c}\text { Overall } \\
\text { fuel type } \\
(\mathbf{N =} \mathbf{1 1 2}) \\
\mathbf{\%}\end{array}$ \\
\hline Fuel wood & 93.3 & 100 & 100 & 97.3 \\
Charcoal & 4.4 & 34.5 & 18 & 23.5 \\
Kerosene & 2.2 & 0 & 0 & 0.88 \\
Agricultural residue & 0 & 6.9 & 0 & 2.5 \\
\hline
\end{tabular}

$\mathrm{N}=$ Number of observation

mothers involved in cooking was $95.2 \%$, $81.2 \%$ and $79.3 \%$ in Chahua, Msangani and Kazimzumbwi correspondingly. Women and especially mothers were more exposed to pollutants originating from cooking activities than men.

Regarding the type of the stove used, it has been observed that in all the three villages, the open fire (three stones) method is the main stove type used. Charcoal stoves still account for a very small percentage. The study also revealed that fuel wood was sometimes used in charcoal stoves instead of charcoal.

\section{Housing and kitchen characteristics}

Housing characteristics in both monitored and non-monitored households were remarkably similar. The housing characteristics show that most of the houses had mud floors and walls and thatched roofs. The average numbers of rooms per house were 2 for Chahua and Kazimzumbwi and 3 for Msangani villages. The results revealed that only $15.6 \%$ of Msangani households have separate kitchens inside the house and thus, cooking is mostly done in rooms used for other purposes such as sleeping and resting. The average plan size of a room is $2.5 \mathrm{~m} \times 2.5$ $\mathrm{m}$. The average kitchen height was $2.6 \mathrm{~m}$. The size of a specially dedicated kitchen was often less than that. In Chahua village, $38 \%$ of the households had specific kitchens while at Kazimzumbwi the number was only $27.3 \%$. It is clear that the majority of households had no dedicated kitchens and since cooking was done in bedrooms or sitting rooms, the exposure time was prolonged and thus the risk was increased.

Regarding ventilation, it was observed that in all villages, $92 \%$ of all houses did not have windows for ventilation. In those that did, the windows were often too small to provide adequate ventilation. During combustion of cooking fuels, smoke tends to accumulate in the indoor environment..

\section{Time - activity budget}

The mean time (h) spent by various subgroups of household members at each of the locations during the day are presented in table 2 .

The age groups $0-5$ years and $61-80$ years spend more time indoors at home than other sub-groups. The age groups $0-5$ and 615 years spend more time outdoors than the other two remaining age groups. The overall average shows that each sub-group members spend more time in the indoor environment than in other locations. Children below 5 years spend $85 \%$ of their time indoors while the adults in the 61-80 age group spend about $87 \%$ of their time indoor. It is worth noting that children who are below 5 years of age and adults who are above 61 years spend most of their time in the indoor environment, and thus are in the most vulnerable sub-groups in respect to health effects due to indoor air pollution. The overall time pattern spent by each group in indoor environment is presented in table 3 .

The overall pattern shows that the populations in the three villages spend $76.8 \%$ of their time indoor and only $23.2 \%$ of time is spent in the outdoor environment.

Carbon monoxide

Carbon monoxide levels before cooking
period

Carbon monoxide (CO) levels in the kitchens were established for houses which used fuel wood, charcoal, and kerosene for cooking. In the morning, prior to any cooking, 
the $\mathrm{CO}$ concentrations in households using charcoal stove and kerosene stove were zero while for households using fuel wood, the $\mathrm{CO}$ concentration were above zero (Figure 2). Considering households using fuel wood for cooking (before cooking), which forms the majority of households in Msangani village (Table 1) $30.6 \%$ of the households have CO concentrations which exceed the WHO hourly standard of $30 \mathrm{mg} / \mathrm{m}^{3}$ (Fig. 2).

\section{Carbon monoxide levels during cooking}

The average carbon monoxide concentrations in all households during cooking with fuel wood are presented in Fig. 3 . The average hourly $\mathrm{CO}$ concentrations during cooking with the fuel wood was $325 \pm$ $211 \mathrm{mg} / \mathrm{m}^{3}$, which was much higher than WHO hourly standard of $30 \mathrm{mg} / \mathrm{m}^{3}$.

The average carbon monoxide concentrations during cooking in households using charcoal fuel are presented in Fig. 4.

Table 2: Time spent by each age subgroup per day at different location.

\begin{tabular}{lcccc}
\hline \multirow{2}{*}{ Location } & \multicolumn{5}{c}{ Time (h) spent by each subgroup age at each location in 24 hrs } \\
\cline { 2 - 5 } & $\begin{array}{r}\mathbf{0 - 5} \text { yrs } \\
(\mathbf{N}=\mathbf{9 0})\end{array}$ & $\begin{array}{c}\mathbf{6 - 1 5} \text { yrs } \\
(\mathbf{N}=\mathbf{1 4 5})\end{array}$ & $\begin{array}{c}\mathbf{1 6 - 6 0} \text { yrs } \\
(\mathbf{N}=\mathbf{1 9 2})\end{array}$ & $\begin{array}{c}\mathbf{6 1 - 8 0} \mathbf{~ y r s} \\
(\mathbf{N}=\mathbf{2 6})\end{array}$ \\
\hline Indoor at home & $17.9 \pm 1.2$ & $15.4 \pm 0.9$ & $14.5 \pm 1.3$ & $18.6 \pm 1.2$ \\
Farm/school & $0.8 \pm 0.2$ & $5.2 \pm 0.9$ & $4.0 \pm 1.4$ & $0.8 \pm 0.4$ \\
Indoor other & $2.9 \pm 0.7$ & $1.2 \pm 0.5$ & $3.7 \pm 0.7$ & $2.7 \pm 0.7$ \\
Outdoor & $2.4 \pm 0.5$ & $2.2 \pm 0.3$ & $1.9 \pm 0.8$ & $1.9 \pm 0.6$ \\
\hline
\end{tabular}

$\mathrm{N}=$ Number of individuals; yrs = years

Table 3: Summary of time pattern for each group in indoor environment.

\begin{tabular}{lcc}
\hline Age group (yrs) & $\begin{array}{c}\text { Population Percentage } \\
(\boldsymbol{\%})\end{array}$ & $\begin{array}{c}\text { Weighted average of } \\
\text { Time Spent Indoor (\%) }\end{array}$ \\
\hline $0-5$ & 19.86 & 17.22 \\
$6-15$ & 32.00 & 22.13 \\
$16-60$ & 42.38 & 32.14 \\
$61-80$ & 5.74 & 4.99 \\
Average percentage of time in the & & 76.80 \\
indoor environment (\%) & & \\
\hline
\end{tabular}

yrs $=$ years

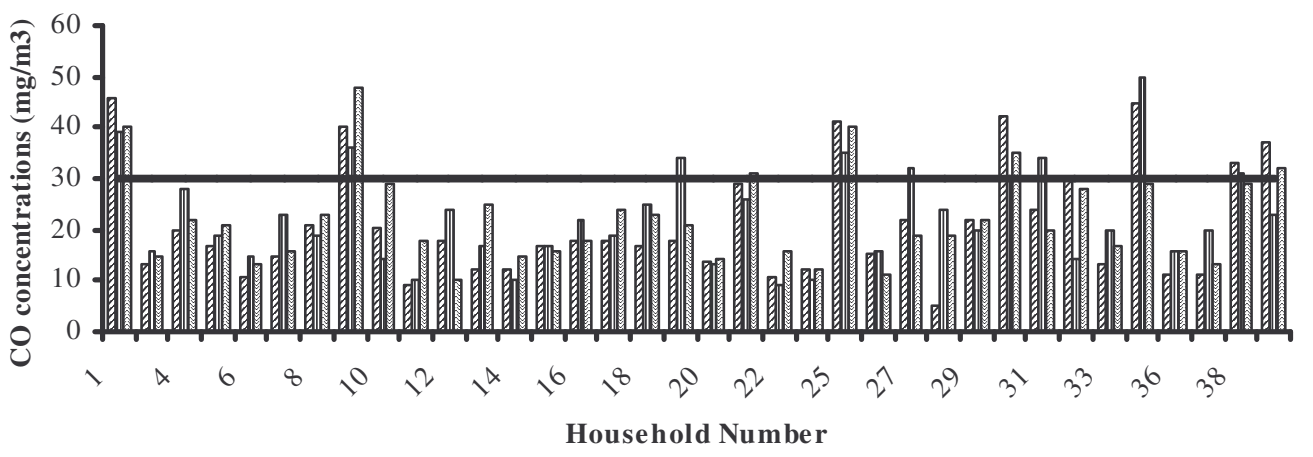

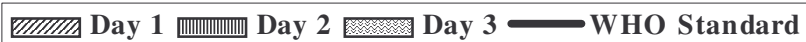

Figure 2: Average carbon monoxide concentrations in the kitchen before cooking for houses using fuel wood 


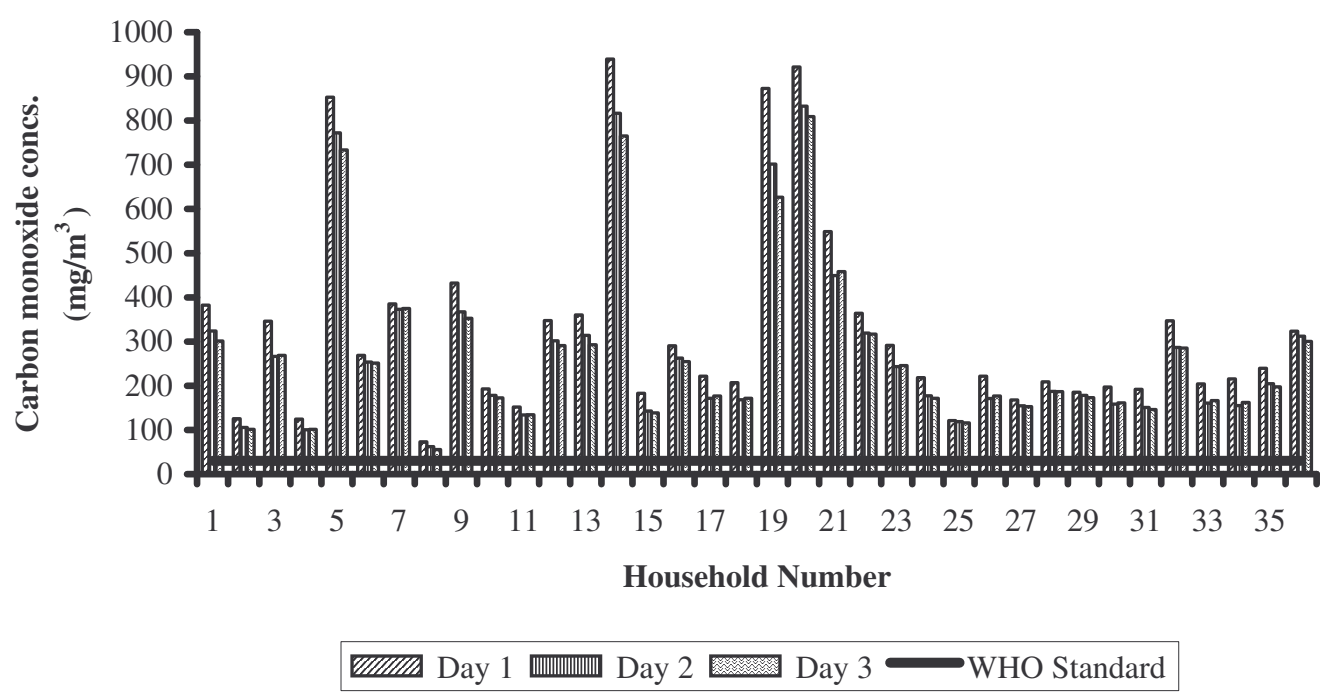

Figure 3: Average carbon monoxide concentrations during cooking with fuel wood in the kitchens in Msangani village. Concs $=$ Concentrations.

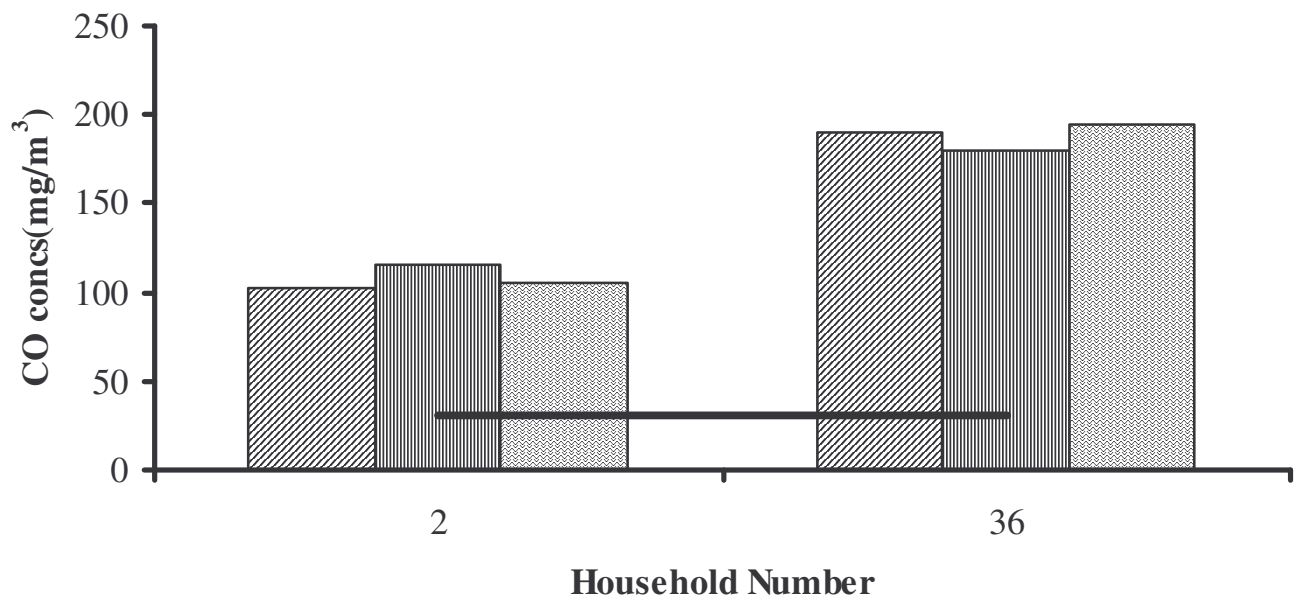

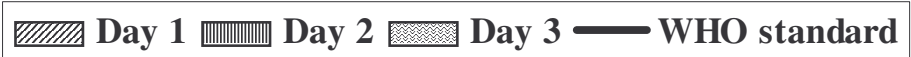

Figure 4 : Average $\mathrm{CO}$ concentrations in kitchens using charcoal. Concs = Concentrations.

CO concentrations during cooking with charcoal stoves are higher than the WHO hourly standard of $30 \mathrm{mg} / \mathrm{m}^{3}$ for the two households (Fig. 4). The overall mean CO concentration for the two households is $148 \pm$ $44 \mathrm{mg} / \mathrm{m}^{3}$. The concentration is lower than that found with fuel wood $\left(325 \pm 211 \mathrm{mg} / \mathrm{m}^{3}\right)$ A kerosene stove was used in only one out of the thirty six households included in this study. The average $\mathrm{CO}$ concentration in that house was $23 \mathrm{mg} / \mathrm{m}^{3}$.

\section{Carbon monoxide after cooking}

The temporal variations of average carbon monoxide concentrations during and after fuel wood and charcoal have been used for cooking are presented in Figures 5 and 6 respectively. 
For both fuel wood and charcoal, the CO levels recorded one-hour after cooking had been stopped was found to be higher than the WHO standard $\left(30 \mathrm{mg} / \mathrm{m}^{3}\right)$ (Figures 5 and 6).

\section{Sulphur dioxide}

The average sulphur dioxide $\left(\mathrm{SO}_{2}\right)$ concentrations in all households during cooking are presented in Fig. 7. Prior to and after cooking, the concentrations of sulphur dioxide were below the detection limits.

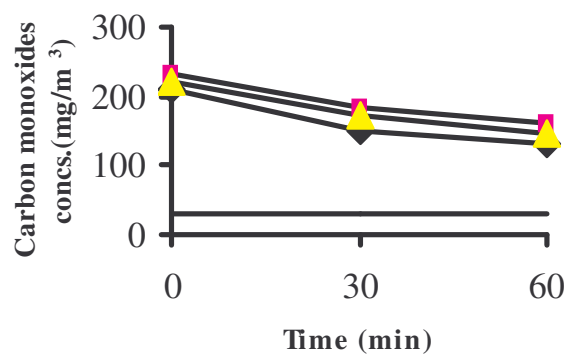

$\begin{array}{ll}\longrightarrow \text { Day } 1 & \longrightarrow \text { Day } 2 \\ - \text { Day } 3 & \longrightarrow \text { WHO standard }\end{array}$

Figure 5: Variation of average carbon monoxide concentrations with time at all households during and after cooking using fuel wood. Concs $=$ Concentrations.
During cooking, the level of $\mathrm{SO}_{2}$ was $26 \pm 2.6 \mu \mathrm{g} / \mathrm{m}^{3}$ which was lower than the WHO standard of $500 \mu \mathrm{g} / \mathrm{m}^{3}$ for an average time of 10 minutes. These results indicate that the sulphur dioxide emission from fuel wood is very low.

The $\mathrm{SO}_{2}$ concentrations before cooking in the two households using charcoal for cooking were below the detection limit. The average sulphur dioxide concentrations in these households during cooking are presented in Fig. 8.

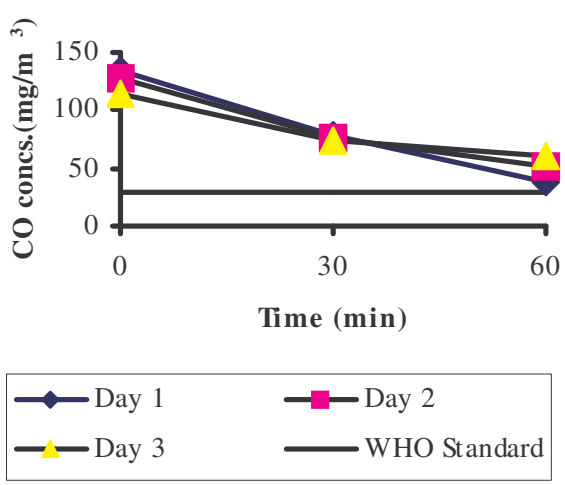

Figure 6: Variation of average carbon monoxide concentrations with time at all households during and after cooking using charcoal. Concs $=$ Concentrations .

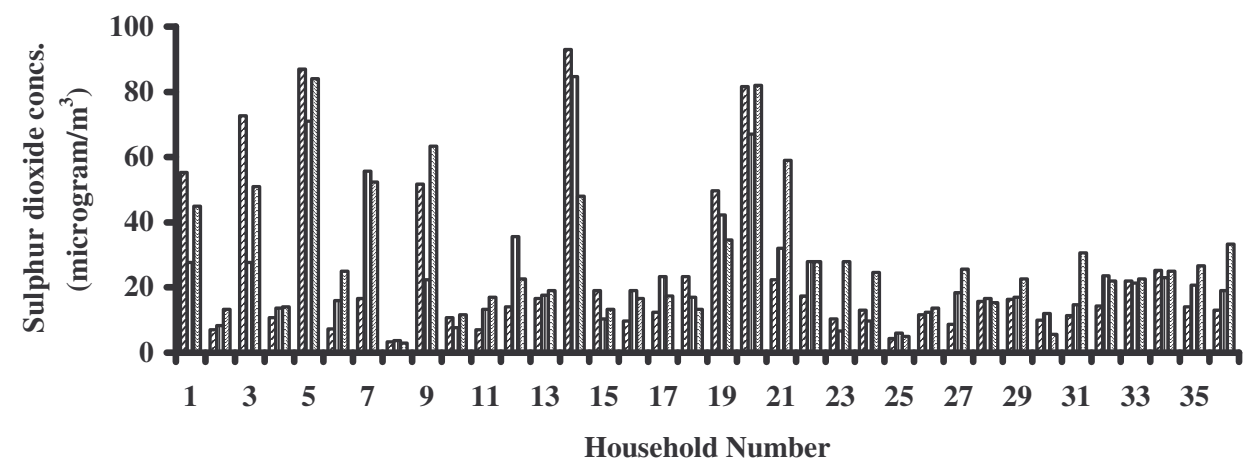

Day 1 血Day 2 圈Day 3

Figure 7: Average sulphur dioxide concentrations for different households using wood fuel for cooking. Concs $=$ Concentrations. 


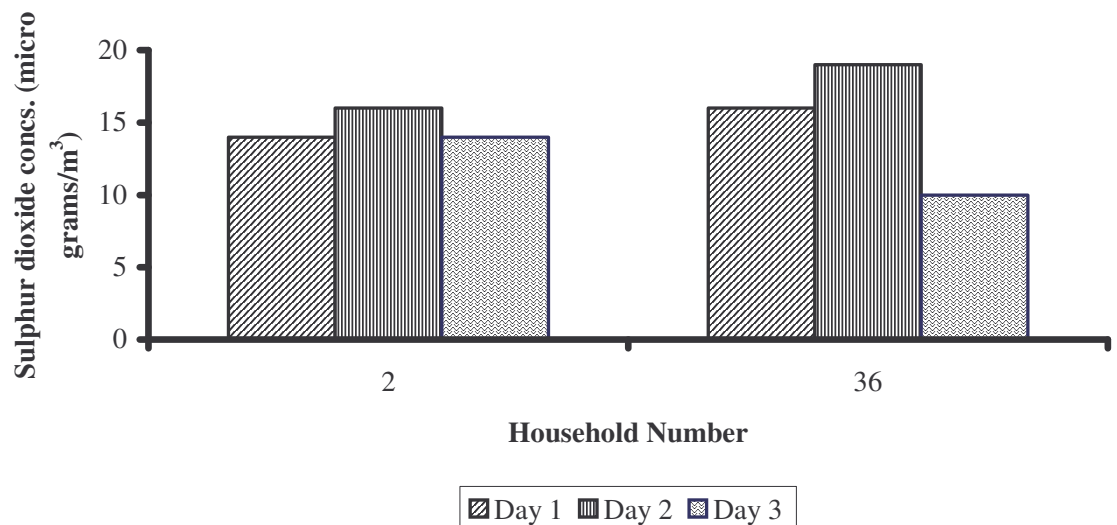

Figure 8: Average $\mathrm{SO}_{2}$ concentrations in the kitchen room during cooking by using charcoal. Concs $=$ Concentrations .

The average sulphur dioxide concentrations measured during cooking were $14.7 \pm 2.3 \mu \mathrm{g} / \mathrm{m}^{3}$

Sulphur dioxide was not detected during cooking with kerosene fuel.

\section{Nitrogen oxides}

The NOx concentrations before cooking in the households using fuel wood were below the limit of detection. During cooking, average NOx concentrations of 27.6 $\pm 0.27 \mu \mathrm{g} / \mathrm{m} 3$ were found.

The average concentration of nitrogen oxides in the kitchens using charcoal for cooking was $15 \pm 2.8 \mu \mathrm{g} / \mathrm{m}^{3}$.

\section{Suspended Particulate Matter}

Hourly average concentrations of Suspended Particulate Matter (SPM) during cooking with fuel wood are presented in Fig. 9.

The hourly average SPM concentration during cooking ranged from $13,571 \mu \mathrm{g} / \mathrm{m}^{3}$ to $305,798 \mu \mathrm{g} / \mathrm{m}^{3}$. The overall hourly SPM average concentration was $123534 \mu \mathrm{g} / \mathrm{m}^{3}$.

\section{The performance of Single Compartment Model}

The performance Single Compartment Model was determined by comparing the average measured carbon monoxide concentrations in the households with the average model predicted carbon dioxide concentrations using Equation 2 for the 40 households in Msangani, Coast Region.
The ratios of measured and model predicted carbon monoxide concentrations are presented in Fig. 10. The average ratio of measured and model predicted carbon monoxide concentrations for the 40 households is $1.1 \pm 0.3$, indicating that the performance of the model is satisfactory.

The correlation coefficient $\left(\mathrm{r}^{2}\right)$ between the measured and modeled concentration is 0.90. . The linear regression coefficient between the measured and predicted concentration is 0.809 (Fig. 11).

\section{DISCUSSION}

Cooking characteristics and time - activity budget

An observation that women and especially mothers were more exposed to pollutants originating from cooking activities than men made in this study is similar to findings from a previous study by Smith et al., (2000) who concluded that most of the mothers in the developing countries are the main cooks and are thus, exposed to a high amount of pollution from the combustion of the fuel wood. Observation that, the overall populations in the three villages in Coast Region spend $76.8 \%$ of their time indoor agrees with studies conducted in USA which revealed that on average, American people spend $80 \%$ of their time in the indoor environment (Murray et al., 1996). The Americans spend slightly more time in the indoor environment compared to Tanzanians, probably because of the difference in the weather conditions and nature of occupations 


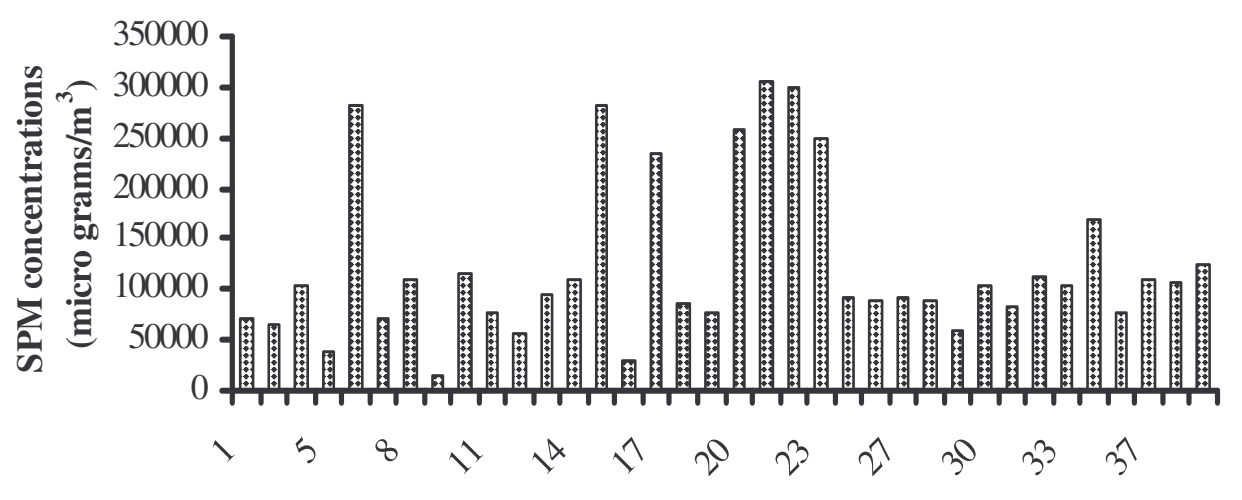

Household Number

\section{国 Average SPM(microgram/m3)}

Figure 9: Average Suspended Particulate Matter concentrations for households using fuel wood for cooking.

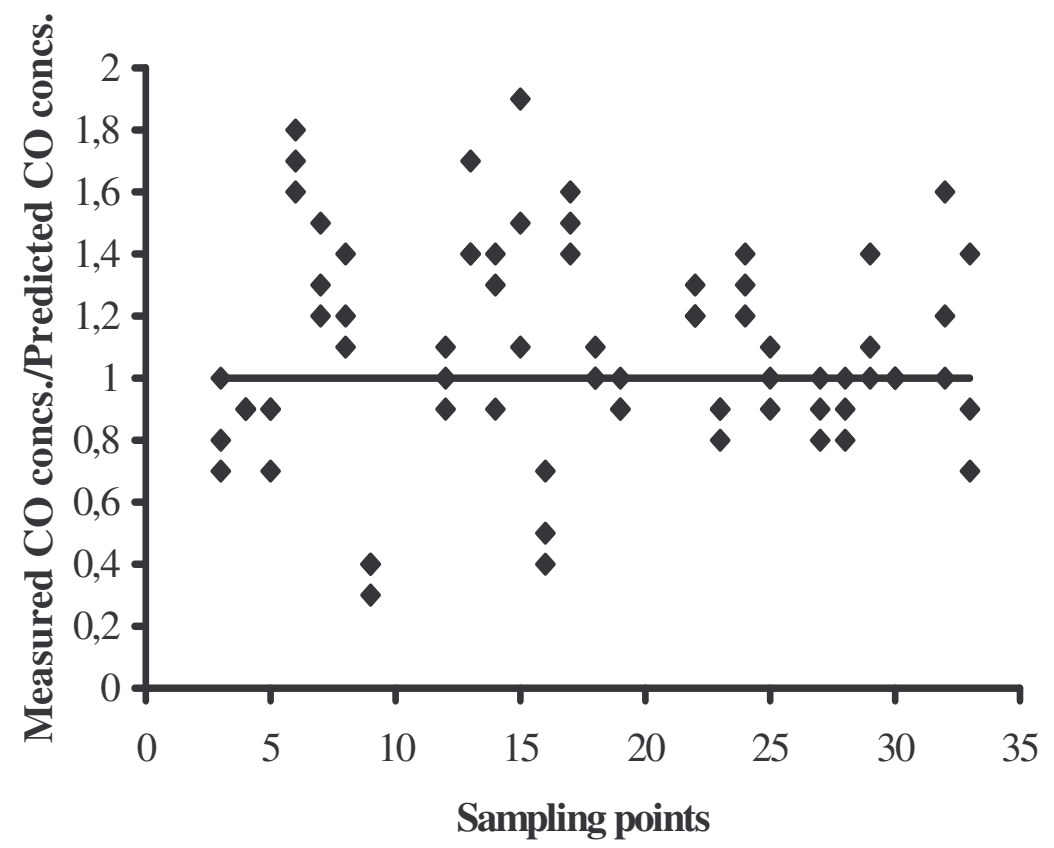

Fig. 10: Comparison of Measured and Modeled Carbon Monoxide Concentrations. Concs $=$ Concentrations

of the majority of the people in the two countries.

\section{Carbon monoxide}

The measured high $\mathrm{CO}$ concentration even before cooking for some houses may be due to house design, house orientation with respect to dominant wind direction, type of food being cooked, and building materials. All these aspects can influence pollutant dilution, smoke extraction from the kitchen, and the amount of $\mathrm{CO}$ emitted during cooking. The 


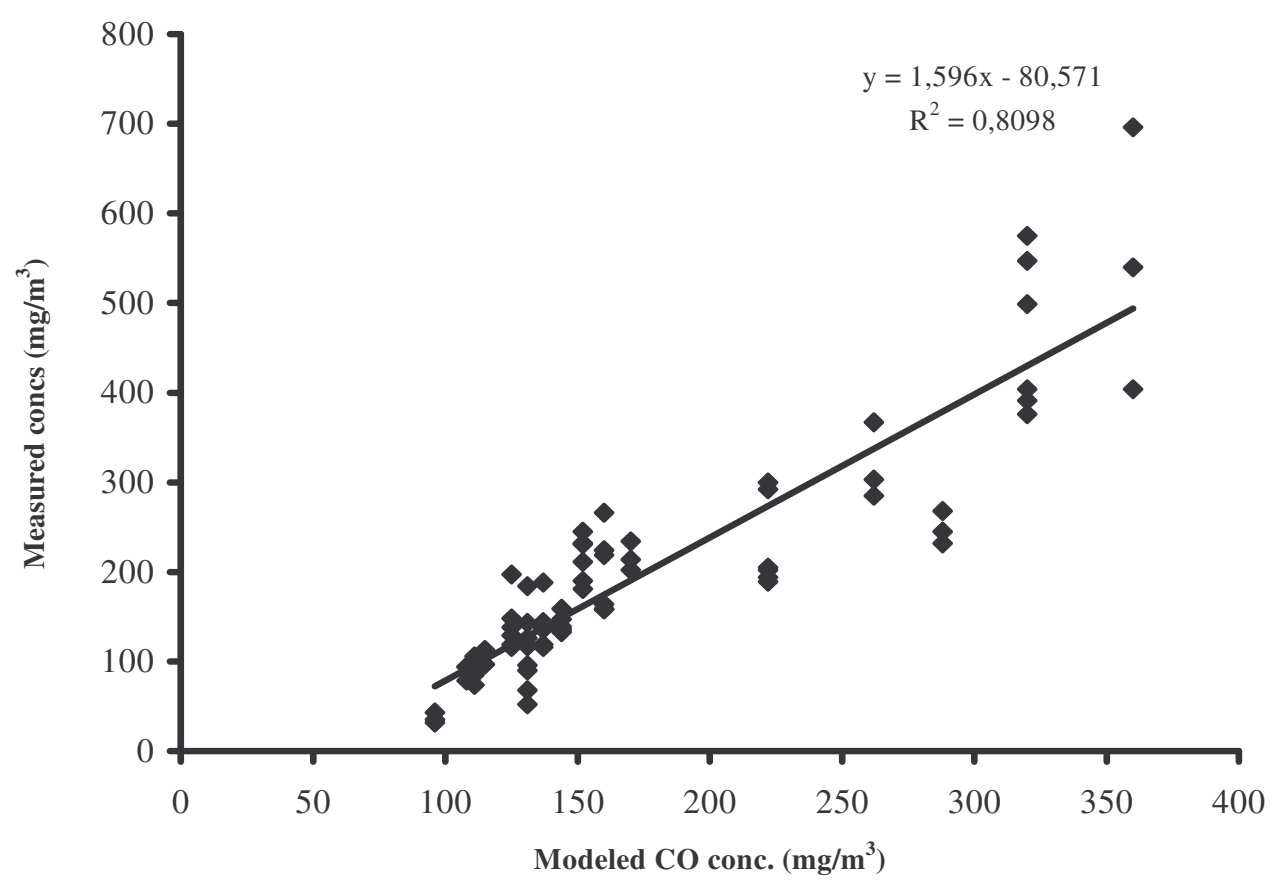

Figure 11: Relationship between the measured and modeled carbon monoxide concentrations.

observed high $\mathrm{CO}$ concentration compared with WHO standard during cooking (Fig. 3) might be a result of inadequate ventilation as most of the houses had no windows and hence little ventilation. The high standard deviation may be a result of several factors such as differences in the type of trees used as fuel wood, and building design including number and size of windows for the few houses which had windows. In terms of $\mathrm{CO}$ emission, whereas fuel wood (Fig. 3) and charcoal fuel (Fig. 4) were both polluting the indoor environment, kerosene could be considered tolerable. Average CO concentrations established in this study when cooking with kerosene were however higher than levels reported in a study conducted in India which reported an average concentration of $14 \mathrm{mg} / \mathrm{m}^{3}$ for households using kerosene fuel (Patel and Raiyan, 1995). The observed differences may be a result of varying housing design which includes ventilation space design and provision of smoke chimneys.

\section{Suspended Particulate Matter}

Suspended Particulate Matter (SPM) concentrations established in the present study are comparable to levels recorded at Pradesh, India which ranged from $200 \mathrm{mg} / \mathrm{m}^{3}$ to $30,000 \mathrm{mg} / \mathrm{m}^{3}$ (Balakrishnan et al., 2004). The overall hourly SPM average concentration of $123534 \mu \mathrm{g} / \mathrm{m}^{3}$ determined in this study exceeds the WHO standard of $150 \mu \mathrm{g} / \mathrm{m}^{3}$. The observed wide range of SPM may be a result of varying housing design and especially the ventilation systems. The big SPM variance is in agreement with results from previous work which suggested that; particulate matter range in homes using biofuels depends on the type of fuel, stove and housing design (Smith et al., 2000).

\section{The performance of Single Compartment Model}

Observed high correlation coefficient $\left(\mathrm{r}^{2}\right)$ between the measured and modeled concentration indicates that the measured concentrations have a strong association with the modeled concentration. 
Moderately high linear regression coefficient $\left(\mathrm{R}^{2}\right)$ between the measured and predicted concentration (Fig. 11), indicate that there is a good linear relationship between the measured and modeled data. The average ratio of measured and model predicted carbon monoxide concentrations is approaching 1 which shows that the model predicted concentrations approximate the measured values. A Single Compartment Model provided a satisfactory approximation of the measured $\mathrm{CO}$ concentrations, and thus, it can be used for the prediction of $\mathrm{CO}$.

\section{Conclusions}

Based on the findings of this study, the following conclusions are drawn:

1. Of the three fuels considered namely fuel wood, charcoal, and kerosene that are used the most in rural area in the Coast Region, fuel wood is the mostly used type. Overall more than $95 \%$ of the surveyed households used fuel wood for cooking. The three stone stove is the main type of stove used in the study area and was used by more than $90 \%$ of the surveyed households. Time-activity patterns revealed that the populations in the three villages spend about $76.5 \%$ of their time indoors.

2. Women undertake most of the cooking in the interviewed households. Hence, women and especially mothers are more exposed to pollutants originating from cooking activities than men. The percentage of mothers involved in cooking in the surveyed villages ranged from $79.3 \%$ to $95.2 \%$.

3. Hourly average $\mathrm{CO}$ concentrations in kitchens during cooking with fuel wood and charcoal were above the WHO standard of 30 $\mathrm{mg} / \mathrm{m}^{3}$. The average CO levels during and after cooking by kerosene were below the WHO standard. CO concentrations before cooking for households using fuel wood were below the WHO standard for $69.4 \%$ of the households. Indoor hourly average pollutant concentrations of $\mathrm{CO}$ during cooking for households that use fuel wood and charcoal in the kitchen were $325 \pm 211$ and $148 \pm 44$ $\mathrm{mg} / \mathrm{m}^{3}$ respectively. $\mathrm{CO}$ levels exceeding the WHO standard were detected 12 hours after cooking with wood fuel implying that there is poor ventilation.

4. Sulphur dioxide concentrations at all households before and after cooking periods were below the limit of detection for all fuel type used. Sulphur dioxide concentrations during cooking for fuel wood, charcoal and kerosene were $26 \pm 2.6 \mu \mathrm{g} / \mathrm{m}^{3}, 14.7 \pm 2.3$ $\mu \mathrm{g} / \mathrm{m}^{3}$, and not detected correspondingly.

5. Nitrogen oxides concentrations at all households before and after cooking were below the limit of detection for all fuel type used. Nitrogen oxides concentrations during cooking were $27.6 \pm 0.27 \mu \mathrm{g} / \mathrm{m}^{3}, 15 \pm 2.8$ $\mu \mathrm{g} / \mathrm{m}^{3}$ and not detected for fuel wood, charcoal, and kerosene correspondingly.

6. The hourly average Suspended Particulate Matter concentrations during cooking with fuel wood was extremely high and ranged from $13571 \mu \mathrm{g} / \mathrm{m}^{3}$ to $305798 \mu \mathrm{g} / \mathrm{m}^{3}$.

7. A single compartment model provided a satisfactory approximation of the measured $\mathrm{CO}$ concentrations with the average ratio of measured $\mathrm{CO}$ concentrations / modeled $\mathrm{CO}$ concentrations of 1.1. The correlation coefficient between the measured and calculated CO concentration was 0.90. The linear regression coefficient $\left(\mathrm{R}^{2}\right)$ between the measured and predicted $\mathrm{CO}$ concentrations was 0.81 .

\section{Recommendations}

1. Installation of chimneys in kitchens and provision of adequate windows in terms of size and number be implemented. Windows also ought to be properly located in order to create effective airflow. These steps are expected to increase the air exchange rate while at the same time resulting in the extraction of CO and SPM from the indoor environment.

2. A deliberate effort be made by the Government and other stakeholders to encourage the use of renewable energy technologies and natural gases which is available in Tanzania.

3. To protect the indoor air from heavy pollution, cooking could be undertaken in the outdoor environment when the weather permits. Alternatively, a dedicated kitchen may also serve to ensure that the main house is spared from significant pollution.

4. Encourage communities in rural area to use kerosene for cooking, since it has been established that kerosene is less polluting compared to fuelwood and charcoal. Considering that kerosene is more expensive than wood fuel and charcoal in many rural areas, the Government could look into a 
possibility of subsidizing kerosene in order to make it more affordable to people in the low income bracket. This will not only reduce indoor air pollution but also minimize deforestation as well as health care costs.

5. Application of a Single Compartment Model in the prediction of CO concentrations is encouraged as a way minimizing resources used for measuring CO concentrations. This should be coupled with the determination of the relevant input parameters for various situations.

6. Public awareness campaigns should be conducted in rural Tanzania, to educate communities to the extent of indoor air pollution, the impact to communities and available mitigation measures. Cultural factors such as the requirement that women do most of the cooking, which ultimately results in greater expose to pollutants for women and children should be discussed in these campaigns.

\section{REFERENCES}

Balakrishnan K, Smith RK, Sambandam S, Ramaswamy P, Mehta S. 2004. Exposure Assesment for respirable particulates associated with household fuel in rural districts of Andhra, Pradesh, India. Journal of Exposure Analysis and Environmental Epidemiology, 14: 514525.

Cleary GJ, and Blackburn CRB. 1968. Air pollution in native huts in the highlands of New Guinea. Archives of Environmental Health, 17: 785-794.

Combustion Analyzer CA-6200-CALc. Manual (http://www.tsi.com)

Dasgupta S, Huq M, Khaliquzzaman M, Pandey K, Wheeler D. 2006.Indoor air quality for poor families: new evidences from Bangladesh. Indoor Air, 16: 426 444.

Fischer SL, Koshland CP. 2007. Daily and peak $1 \mathrm{~h}$ indoor air pollution and driving factors in a rural Chinese village. Environmental Science \& Technology, 41: 3121-3126.

Hong C. 1995. Report on Global Burden of Disease from Air Pollution. World Health Organization: Geneva.

Jackson MM. 2004. The contribution of vehicles to air pollution in the City of
Dar-es-Salaam. Proc. of Better Air Quality in the cities of Africa Conference, APINA: Johannesburg, South Africa.

Jackson MM. 2005. Roadside Concentration of Gaseous and Particulate Pollutants and Risk Assessment in Dar-es-Salaam, Tanzania. Journal of Environmental Monitoring and Assessment, 104: 385 407.

Mestl HES, Aunan K, Seip HM, Wang S, Zhao Y, Zhang D. 2007. Urban and rural exposure to indoor air pollution from domestic biomass and coal burning across China. Science of the Total Environment, 377: 12-26.

Mtango FD, Neuvians D, Broome CV, Hightower AW, Pio A. 1991. Risk factors for death in children under five years old in Bagamoyo district, Tanzania, Tropical Medicine and Parasitology, 229-233.

Murray C, Lopez A.. 1996. The Global Burden of Disease: Global Burden of Disease and Injury Serie. Cambridge, Harvard School of Public Health on behalf of the World Health Organization and the World Bank.

Musabila M. 2002. Street-Levels Ambient Air Quality in Dar-es_Salaam. MSc Dissertation in Environmental Science, University of Dar-es- Salaam.

NEMC. 1993. Report on urban air quality monitoring - pilot project. National Environmental Management Council.

Othman OC. 1996. A study on ambient air quality of Dar-es-Salaam. Proc. of the 5th SADC Seminar on Applied Research in Conservation and Land Management, Windhoek, Namibia.

Parikh J, Balakrishnan K, Laxmi V, Biswas H, Marg GV, Nagar S, Goregoan E. 2004. Exposure to Air pollutants from combustion of cooking fuels- A case study of rural Tamil Nadu. J. Energy, 106: 312 - 321 .

Rumchev K, Spickett JT, Brown HL, Mkhweli B. 2007. Indoor air pollution from biomass combustion and respiratory symptoms of women and children in a Zimbabwean village. Indoor Air, 17: 468-474.

Smith KR, Samet JM, Romieu I, Bruce N. 
2000. Indoor Air Pollution in Developing Countries and Acute Lower Respiratory Infections in Children. iThorax, 55: 518-532.

Sofoluwe GO. 1968. Smoke pollution in dwellings of infants with bronchopneumonia. Archives of Environmental Health, 16: 670-672.

United Republic of Tanzania National. Energy Policy. 2000. Government Printers, Dar es Salaam.

Warwick H, Diog A. 2004. Smoke - the killer in the kitchen: Indoor air pollution in developing countries. ITDG Publishing. http://practicalaction.org/docs/smoke/ itdg\%20smoke\%20report.pdf

WHO. 1999. Global Air Quality Guidelines. WHO: Geneva.

WHO. 2002. World Health Report: Reducing Risks, Promoting Healthy Life. WHO: Geneva.

Zhang J, Smith K.R, Uma R, Ma Y, Kishore.VN, Lata K, Khalil MAK, Rasmussen RA, Thorneloe, ST. 1999. Carbon monoxide from cookstoves in developing countries. Journal of Global Change Science, 1: 366 -375. 